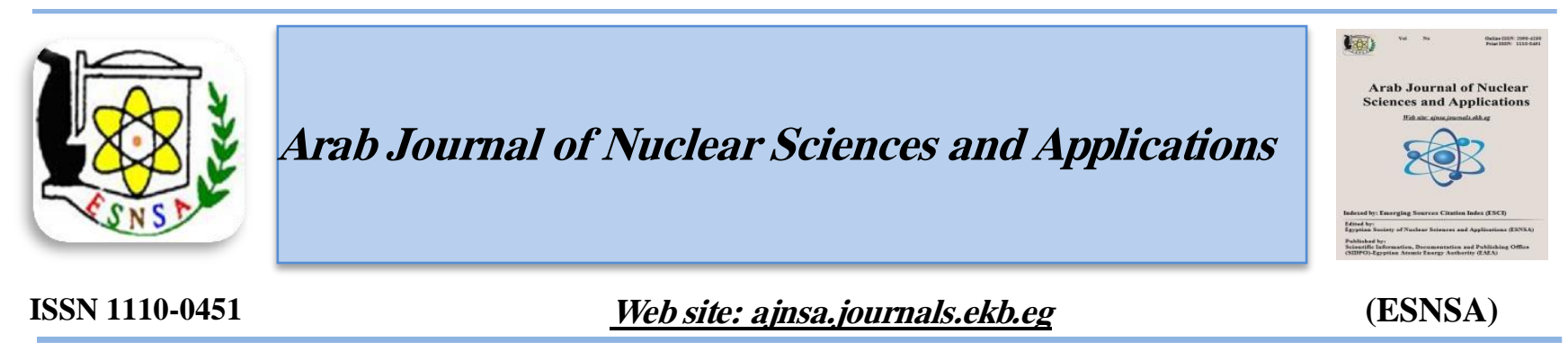

\title{
Effect of Cobalt Chloride on the Optical Properties of PVA/PEG Blend
}

\author{
E.A. El-sayd, A.A. Ibrahiem, R.M. Ahmed* \\ Physics Department, Faculty of Science, Zagazig University 44519, Zagazig, Egypt
}

Received $27^{\text {th }}$ Jan. 2018 Different composite films of cobalt chloride $\left(\mathrm{CoCl}_{2}\right)$ embedded in a blend of (poly vinyl alcohol (PVA) Accepted 21 ${ }^{\text {st }}$ Feb 2018 /poly ethylene glycol (PEG) 72/28 wt. \%) were prepared by the solution casting technique. Fourier Transform infrared (FT-IR) spectroscopy was used to identify the effect of $\mathrm{CoCl}_{2}$ on the characteristic functional groups of both PVA and PEG. A shift in the absorption edge of the pure blend was observed by adding $\mathrm{CoCl}_{2}$ which indicates a decrease in the energy gap $\left(\mathrm{E}_{\mathrm{g}}\right)$ values based on the $\mathrm{CoCl}_{2}$ content. By increasing the content of $\mathrm{CoCl}_{2}$, the refractive index, the Urbach energy, the dispersion parameters, the moments of the optical spectrum and the static dielectric constants show a reduction in their values compared to those of the pure blend. The oscillator energy gap $E_{0}$ equals about $2.23 E_{g}$, for the different composites. The calculated values of the penetration depth, for all the composites, exhibit an increase by increasing the wavelength whereas they decrease in the region of the absorption band of the $\mathrm{CoCl}_{2}$ from $420 \mathrm{~nm}$ to $750 \mathrm{~nm}$ depending on the $\mathrm{CoCl}_{2}$ content. The optical conductivity of the composites has been increased in the region of the absorption band of the $\mathrm{CoCl}_{2}$.

Keywords: Cobalt chloride/Optical conductivity/Energy band gap/Urbach energy/Optical dispersion parameters

\begin{abstract}
Introduction
Composite materials are described as materials that contain two or more different phases, which are not the same in their chemical and physical properties and separated from each other by a distance interface. Due to their ability to be applied in many technological applications, polymer composites have attracted great attentions. They are effectively used in the daily applications as radio frequency interference shielding for electronic devices and photo thermal optical recording. Polymeric materials are essentially nominated to be used in the electronic applications [1].
\end{abstract}

A previous study by the author of the present work [2] shows that polyvinyl alcohol is a kind of polymers whose physical properties can be modified by incorporating it with appropriate fillers or polymers. Because of its high charge storage capacity, high flexibility and its good dielectric strength, polyvinyl alcohol (PVA) has been incorporated into many applications of industry. PVA is a semi-crystalline polymer and it plays a main role in the biomedical applications due to its good chemical resistance, simple preparation and excellent biodegrade ability. The carbon chain backbone of PVA with hydroxyl groups provides a hydrogen-bonding source to improve the creation of polymer complexes $[3,4]$. On the other hand, PEG has important characteristics as superb water solubility, being good protein adsorption resistance, low toxicity and poor immunogenicity. In addition, no observed damage is observed when PEG is contacted with the lips or skin, so it is suitable to be used in different applications as coating material for the biotechnical applications [5]. PEG can be used as a binder in ceramic preparation and its considerable

Corresponding author: rania.7.8.2016@gmail.com

DOI: 10.21608/ajnsa.2018.2768.1049

(C) Scientific Information, Documentation and Publishing Office (SIDPO)-EAEA 
physical and chemical properties enable it to be used in variant industrial applications [6].

Transition metal halides play an essential role on modifying the structure and the physical properties of the hosting polymer depending on the kind of interaction between them and the hosting matrix. In order to improve the physical properties of a polymeric material, inorganic fillers including $\mathrm{Co}_{3} \mathrm{O}_{4}, \mathrm{Zno}, \mathrm{TiO}_{2}, \mathrm{SnO}_{2}$ and $\mathrm{PdCl}_{2}$ have been utilized. One of the most interesting inorganic fillers is cobalt chloride $\left(\mathrm{CoCl}_{2}\right)$, which is produced in the form of hexahydrate $\left(\mathrm{CoCl}_{2} \cdot 6 \mathrm{H}_{2} \mathrm{O}\right)$ and it employed in manufacturing of vitamin B12, catalyst preparation, electroplating and painting on glass and porcelain. $\mathrm{CoCl}_{2}$ is also acting as silica gel, computer memory devices, invisible ink and water indicator [7]. Furthermore, it is used in variant humidity sensing applications. Due to the creation of $\mathrm{Co}^{2+}, \mathrm{CoCl}_{2}$ is nominated as an effective electron acceptor in different research fields [2].

In the present study, films of different contents of $\mathrm{CoCl}_{2}$ embedded in a blend of PVA/PEG 78/28 wt.\% were prepared by solution casting method. FT-IR was used as a powerful tool to determine the functional groups of the different composites. The effect of $\mathrm{CoCl}_{2}$ on the optical properties of the hosting blend was investigated from the reflection and the absorption measurements. Also, different optical parameters were calculated for this purpose including Urbach energy, optical energy gap, refractive index, optical conductivity and some other important parameters.

\section{Experimental Techniques \\ Sample preparation}

PVA $\left(\mathrm{M}_{\mathrm{w}} \approx 115,000\right.$ g. $\left.\mathrm{mol}^{-1}\right)$ and cobalt chloride $\left(\mathrm{CoCl}_{2}\right)$ were purchased from India while PEG $\left(\mathrm{M}_{\mathrm{w}}\right.$ $\approx 4000 \mathrm{~g} \cdot \mathrm{mol}^{-1}$ ) was obtained from (Fluka chemical Co., Germany). These two homopolymers were absolutely used without further purifications. Solution casting method was used to prepare the films of the composites. The powder of PVA was dissolved in distilled water under heating at $80^{\circ} \mathrm{C}$ with a gentle stirring for 120 minute then left to reach the room temperature. On the other hand, the powders of PEG and $\mathrm{CoCl}_{2}$ were dissolved, separately, in distilled water at room temperature for 60 minutes. The solution of PEG was added slowly to PVA under stirring for 60 minutes to form the blend of (PVA/PEG 72/28 wt. \%). Composites of different cobalt chloride contents $(0$,
4.76, 11.1, 14.0, 16.2 and 19.2 wt. \%) were prepared by embedding in the blend of (PVA/PEG $72 / 28$ wt. \%). The content of cobalt chloride, W (wt. \%), was calculated from the equation,

$W(w t \%)=\frac{w_{f}}{w_{p}+w_{f}} \times 100$,

where $\mathrm{w}_{\mathrm{f}}$ and $\mathrm{w}_{\mathrm{p}}$ represent the filler and the polymer weights, respectively. Consequently, the solutions of the composites were poured in glass dishes in vacuum at $318 \mathrm{~K}$ for $48 \mathrm{~h}$. After cooling to room temperatures, the films were taken out and kept in desiccators to ensure good drying. The produced films had an average thickness of $\approx$ $0.0053 \pm 0.001 \mathrm{~cm}$.

\section{$U V$ - Visible measurements}

UV- visible spectrophotometer JASCO (V-550) was used for the measurements of UV/Vis absorption spectra in a range of wavelengths from (190-900) nm.

\section{Reflection measurements}

UV-Vis-NIR spectrometer (UV-3101 PC) shimadzu was used to detect the specular reflection spectra in a range of wavelengths from $(190-900) \mathrm{nm}$.

\section{FT-IR Measurements}

Fourier Transform Infrared Spectrometer (FTIR 460 plus) was used to measure FT-IR spectra in the wave number range $\left(4000-400 \mathrm{~cm}^{-1}\right)$.

\section{Results and Discussion}

\section{FT-IR Characterization}

FTIR spectroscopy was used to discover the possible interaction between the functional groups of PVA and PEG and the cobalt chloride as shown in Fig (1). In a range of wave numbers from 4000 $\mathrm{cm}^{-1}$ to $400 \mathrm{~cm}^{-1}$, FT-IR absorption spectra were measured for some selected composites of the different contents of $\mathrm{CoCl}_{2}(0,4.76,14.0$ and 19.2 wt.\%) embedded in the blend. For the pure blend of (PVA/PEG 72/28 wt.\%), Table 1 illustrates a characteristic absorption band in the range of $3000-3400 \mathrm{~cm}^{-1}$ which is ascribed to the symmetrical stretching vibration of $\mathrm{O}-\mathrm{H}$ group. The bands existed at $2893 \mathrm{~cm}^{-1}$ and $1707 \mathrm{~cm}^{-1}$ are attributed to $\mathrm{C}-\mathrm{H}$ asymmetric stretching vibration of the alkyl group and to the $\mathrm{C}=\mathrm{O}$ stretching vibration of vinyl acetate group of PVA, respectively. The $\mathrm{CH}_{2}$ bending group and $\mathrm{CH}_{2}$ wagging vibrations appeared at $1443 \mathrm{~cm}^{-1}$ and $1346 \mathrm{~cm}^{-1}$, respectively. The observed band at $1098 \mathrm{~cm}^{-1}$ is corresponding to the $\mathrm{C}-\mathrm{O}$ stretching 
vibration of an acetyl group. C-OH group of PEG was observed at $948 \mathrm{~cm}^{-1}$. The stretching vibration band of $\mathrm{C}-\mathrm{C}$ group was detected at a wave number of $\approx 844 \mathrm{~cm}^{-1}[2,8]$. The positions of some bands of PVA and PEG, in the different compositions, detected at 1443, 1098, 948, 2893 and $1346 \mathrm{~cm}^{-1}$ were slightly shifted upon incorporation of $\mathrm{CoCl}_{2}$ into the blend. This indicates the presence of polymeric structure changes. The disappearance of $\mathrm{C}=\mathrm{O}$ symmetric stretching bond in all the composites which was located at $1707 \mathrm{~cm}^{-1}$ in the blend can be attributed to the molecular interaction of $\mathrm{CoCl}_{2}$ with many reaction sites of the blend [2].

\section{$U V-$ Visible spectroscopy}

Studying the optical absorption spectra is one of the most interesting methods used in understanding the structure and energy gap of polymeric materials [9]. The measurements of the optical absorption were achieved to determine the effect of embedding $\mathrm{CoCl}_{2}$ in the blend of PVA/PEG 72/28 wt.\%. Fig. (2) illustrates the absorption spectra for composites of $\mathrm{CoCl}_{2}(0,4.76,11.1,14.0,16.2$ and 19.2 wt. \%) embedded in PVA/PEG 72/28 wt. \% which were measured in the UV/vis region (190900) $\mathrm{nm}$. For all the composites, an absorption peak was detected at $\approx 522 \mathrm{~nm}$ which is a characteristic of octahedral structure around the Co (II) ion due to the electronic transition ${ }^{4} T_{1 g}(F) \rightarrow{ }^{4} T_{2 g}(p)\left(v_{3}\right)$. Moreover, it is reasonable to assign the absorption band detected at $\approx 674 \mathrm{~nm}$ to ${ }^{4} T_{1 g} \rightarrow{ }^{4} A_{2 g}$ transition. Also, a shoulder for cobalt chloride concentrations observed at $\approx 626$ $\mathrm{nm}$ is assigned to ${ }^{4} T_{1 g}(F) \rightarrow{ }^{4} A_{2 g}(F)\left(v_{2}\right)$ transition. The position of these bands suggests an octahedral environment around the Co (II) ion [2]. For only the pure blend of PVA/PEG 72/28 wt. \%, an absorption band is observed at about $279 \mathrm{~nm}$ which was ascribed to $\pi-\pi^{*}$ electronic transition[5].

The variation of the absorption coefficient $\alpha\left(\mathrm{cm}^{-1}\right)$ with energy $\mathrm{E}(\mathrm{eV})$ acts as a significant identification for the polymeric materials which provides optical information about them. The absorption coefficient $\alpha\left(\mathrm{cm}^{-1}\right)$ was estimated according to Eq. 1 [10]:

$$
\alpha(v)=\frac{2.303 \times A}{d}
$$

Where $A$ is the absorbance and $d$ is the sample thickness. Fig. (3a-3f) illustrate the variation of $\alpha$ $\left(\mathrm{cm}^{-1}\right)$ with $\mathrm{E}(\mathrm{eV})$ for all the composites which show an increase in the absorption near the edge. This is a result of the creation of neutral excitations and/or the transition of electrons from the valence band to the conduction band. Fig. 3a-3f show a steep rise near the absorption edge and there is a straight line relationship can be determined in the high $\alpha$-region. The absorption edge values were determined from the intercept of extrapolation to zero absorption with photon energy axis [11]. Table (2) illustrates that the calculated values of absorption edges were decreased from $6.26 \mathrm{eV}$ for the pure blend of PVA/PEG 72/28 wt.\%. to 4.67 $\mathrm{eV}$ for the highest content of $\mathrm{CoCl}_{2}$ embedded in the blend.

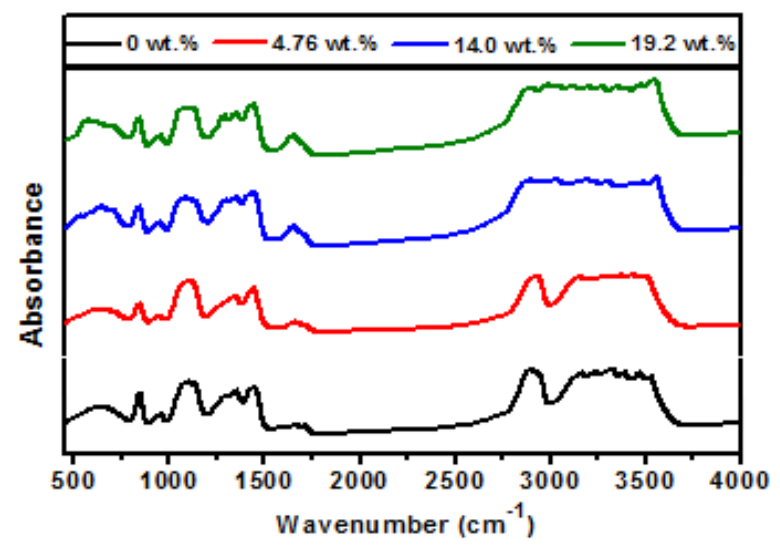

Fig. (1): FT-IR spectra for different contents of cobalt chloride $\left(\mathrm{CoCl}_{2}\right)$ embedded in the blend of PVA/PEG 72/28 wt. \%

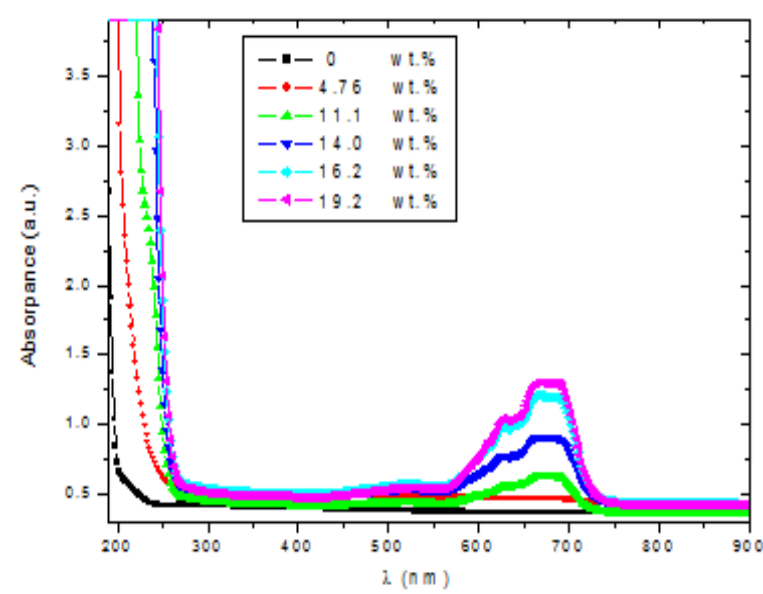

Fig. (2): UV-visible absorption spectra for different contents of cobalt chloride $\left(\mathrm{CoCl}_{2}\right)$ embedded in the blend of PVA/PEG 72/28 wt.\% 
Table (1):

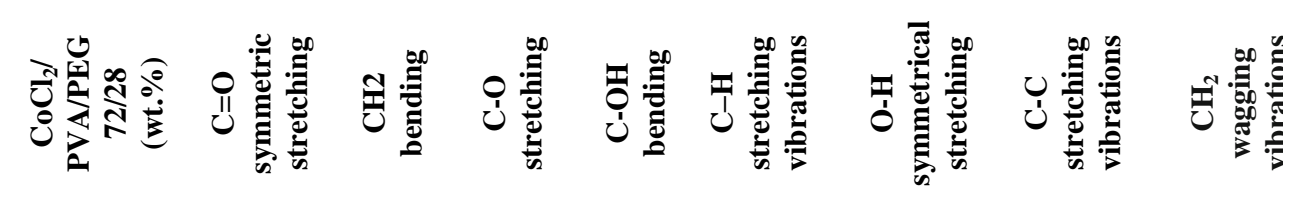

The

\begin{tabular}{ccccccccc}
\hline $\mathbf{0}$ & 1707 & 1443 & 1098 & 948 & 2893 & $3000-3400$ & 844 & 1346 \\
\hline $\mathbf{4 . 7 6}$ & - & 1436 & 1115 & 940 & 2915 & $3148-3364$ & 843 & 1337 \\
\hline $\mathbf{1 4 . 0}$ & - & 1438 & 1076 & 949 & 2885 & $3025-3292$ & 841 & 1350 \\
\hline $\mathbf{1 9 . 2}$ & - & 1430 & 1089 & 950 & 2889 & $3097-3407$ & 841 & 1349 \\
\hline
\end{tabular}

wavenumbers of assignments of the absorption bands deduced from FT-IR spectra for different concentrations of $\mathrm{CoCl}_{2}$ embedded in PVA/PEG 72/28 (wt. \%)
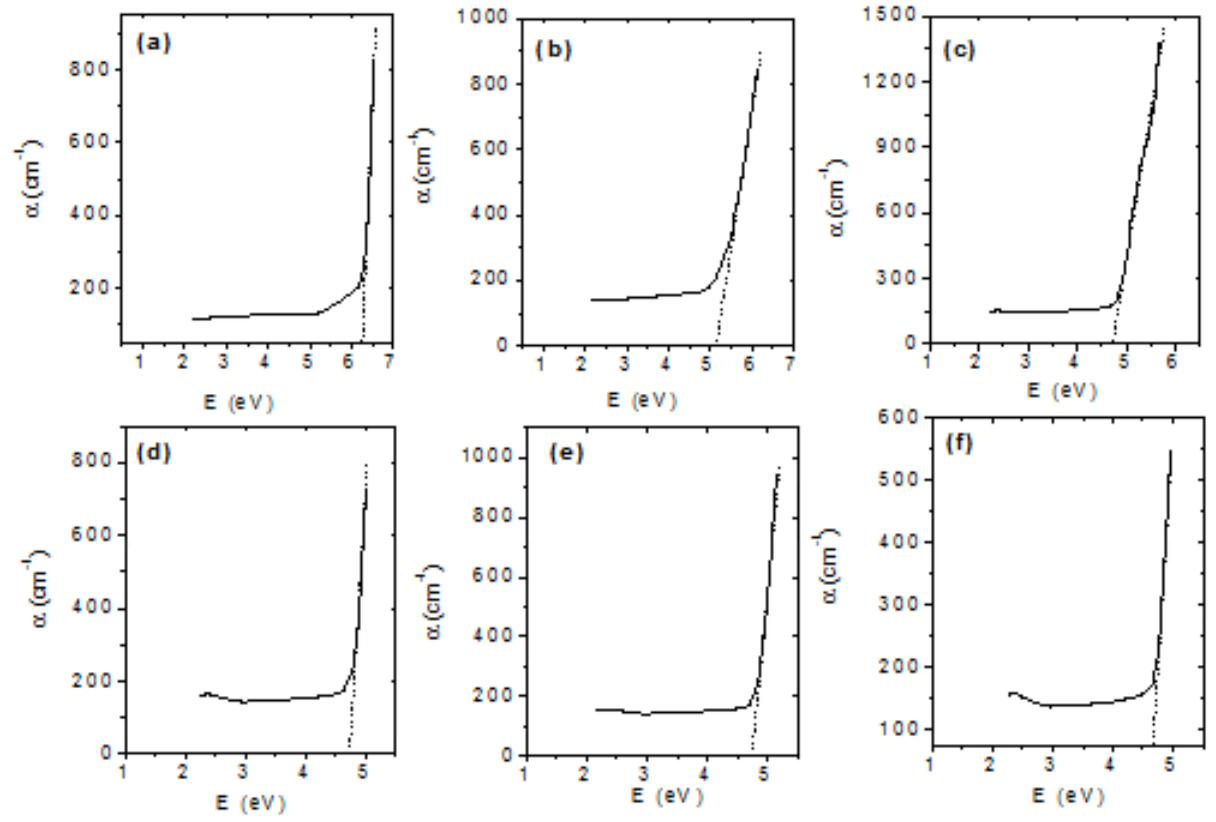

Fig. (3): The variation of the absorption coefficient $(\alpha)$ versus photon energy for cobalt chloride $\left(\mathrm{CoCl}_{2}\right)$ embedded in the blend of PVA/PEG 72/28 wt.\% with different contents (a) 0 wt.\%, (b) 4.76 wt.\%, (c) 11.1 wt.\%, (d) 14.0 wt.\%, (e) 16.2 wt. $\%$ and (f) 19.2 wt.\% 
Table (2): The values of the absorption edge $A_{\text {edg }}$, the optical energy gap $E_{g}$, the Urbach energy $E_{u}$, the dispersion energy $E_{d}$, the single oscillator energy $E_{o}$, the static refractive index $n_{0}$, the static dielectric constant $\varepsilon_{\infty}$, and the moments of the optical spectrum $\left(\mathrm{M}_{1}\right.$ and $\mathrm{M}_{3}$ ) for different concentrations of $\mathrm{CoCl}_{2}$ embedded in PVA/PEG 72/28 (wt\%)

\begin{tabular}{|c|c|c|c|c|c|c|c|c|c|c|}
\hline $\begin{array}{c}\mathrm{CoCl}_{2} / \mathrm{PVA} / \mathrm{P} \\
\mathrm{EG} \\
72 / 28(\text { wt. } \%)\end{array}$ & $\begin{array}{l}\mathbf{A}_{\text {edg }} \\
(\mathrm{eV})\end{array}$ & $\begin{array}{c}\mathbf{E}_{\mathbf{g}} \\
(\mathrm{eV})\end{array}$ & $\begin{array}{c}\mathbf{E}_{\mathbf{u}} \\
(\mathrm{eV})\end{array}$ & $\begin{array}{c}\mathbf{E}_{\mathbf{d}} \\
(\mathrm{eV})\end{array}$ & $\begin{array}{c}\mathbf{E}_{\mathbf{o}} \\
(\mathrm{eV})\end{array}$ & $\mathbf{E}_{\mathbf{o}} / \mathbf{E}_{\mathbf{d}}$ & $\mathbf{n}_{\mathbf{o}}$ & $\boldsymbol{\varepsilon}_{\infty}$ & $\mathbf{M}_{1}$ & $\begin{array}{c}\mathbf{M}_{3}{ }^{*} \\
\mathbf{1 0}^{-3}\end{array}$ \\
\hline 0 & 6.26 & 6.34 & 0.27 & 25.13 & 6.98 & 1.10 & 2.14 & 4.60 & 3.60 & 73.90 \\
\hline 4.76 & 5.14 & 5.85 & 0.69 & 14.41 & 12.39 & 2.12 & 1.47 & 2.16 & 1.16 & 7.576 \\
\hline 11.11 & 4.72 & 5.18 & 0.32 & & & & & & & \\
\hline 14.00 & 4.74 & 4.98 & 0.24 & 10.88 & 11.35 & 2.27 & 1.40 & 1.96 & 0.96 & 7.443 \\
\hline 16.17 & 4.73 & 4.91 & 0.21 & & & & & & & \\
\hline 19.20 & 4.67 & 4.89 & 0.18 & 5.876 & 11.28 & 2.30 & 1.23 & 1.52 & 0.52 & 4.099 \\
\hline
\end{tabular}

\section{Interband transitions}

Davis and Mott formula describes the absorption coefficient for simple parabolic band as a function of photon energy as illustrated by the Eq. 2 [12]:

$$
\alpha E=B\left(E-E_{g}\right)^{m}
$$

where $B$ is a constant, $\mathrm{E}_{\mathrm{g}}$ is the optical band gap, $E$ is the photon energy and $m$ is an index with the values of $2,3,1 / 2$ and $3 / 2$, depending on the nature of electronic transition responsible for the absorption. The dependence of $(\alpha \mathrm{E})^{2}$ on the photon energy $\mathrm{E}(\mathrm{eV})$ for the different composites of $\mathrm{CoCl}_{2}$ embedded in PVA/PEG 72/28 blend are shown in Fig. (4a-4f) which exhibits a linear behavior that proves the existence of the direct transition (i.e., for $m=1 / 2$ ). The optical gap was estimated from the intercept on the energy axis of the linear fit of the large energy data of the plot and tabulated in Table (2).

Table (2): shows a decrease in the values of $E_{g}$, by increasing the $\mathrm{CoCl}_{2}$ content embedded in the blend of (PVA/PEG 72/28). The decrease in the energy gap values is attributed to the formation of the localized states in the band gap by embedding the $\mathrm{CoCl}_{2}$ in the blend [13]. The formed localized states are playing as trapping and recombination centers, which results in a remarkable alteration in the optical band gap. In addition, the change in the structure of the blend of (PVA/PEG 72/28) because of increasing the disorder degree by adding $\mathrm{CoCl}_{2}$ can explain the decrease in the band gap [1].

In amorphous and disordered materials, the detected Urbach tail is important to study well the properties of electronic transport of them. The strains in the network of the material, which are enough to force the states in the forbidden gap, result in the formation of the band tail states that decay exponentially in the band gap. Therefore, the Urbach tail acts as an indicator of the defect levels exist in the forbidden band gap. In this region, the absorption process is due to the transitions between extended states in one band and localized states in the exponential tail of the other band [1]. The Urbach energy was calculated from the following empirical formula [14]:

$\alpha=\alpha_{o} \exp \left(E / E_{u}\right)$

Where, $\alpha_{0}$ is a constant and the Urbach energy is $\mathrm{E}_{\mathrm{u}}$ which is corresponding to the band tail width of the localized states in the band gap. The straight line, observed in plotting $\ln (\alpha)$ versus energy (E) as seen in Fig. (5a-5f), shows that the absorption spectra of the different composites confirm the rule of Urbach and it obeys the interband transition of the quadratic relation. Table (2) illustrates the calculated values of $\mathrm{E}_{\mathrm{u}}$ of all the samples which were estimated from the reciprocal of the slopes of the linear portion that are obtainable in Fig. (5) [15].

The decrease in the Urbach energy value of the polymer blend by increasing the content of $\mathrm{CoCl}_{2}$ is attributed to free radicals or cluster formation [16].

\section{Refractive index and dispersion parameters}

The refractive index of the composites was calculated from the reflection and absorption spectra, in a range of wavelengths from 190 to 900 $\mathrm{nm}$, by using the following relation [10]: 


$$
n=\left(\frac{1+R}{1-R}\right)+\sqrt{\frac{4 R}{(1-R)^{2}}-k^{2}}
$$

Where $\mathrm{R}$ is the reflection and $\mathrm{k}$ is the extinction coefficient, which is known as the imaginary part of the complex refractive index that can be estimated from the Eq. 5 [10]:

$k=\frac{\alpha \lambda}{4 \pi}$

Where $\alpha$ is the absorption coefficient and $\lambda$ is the wavelength. Fig. (6a) shows typical dispersion curves of the refractive index of the different contents of $\mathrm{CoCl}_{2}$ (4.76, 14 and 19.2 wt.\%) embedded in PVA/PEG 72/28 (wt.\%) blend which result from the slow decreasing of the refractive index with increasing the wavelength. A decrease of the refractive index of the composite films was observed by increasing the content of $\mathrm{CoCl}_{2}$, which is owing to localized fluctuation of charged particles in medium. In other words, the decrease in the value of refractive index of the composites compared to that of the pure blend of PVA/PEG $72 / 28$ (wt.\%) can be a result of increasing the interatomic spacing. This is because of intermolecular hydrogen bonding formation between the adjacent $\mathrm{OH}$ groups and $\mathrm{CoCl}_{2}$ [17].

Designing devices and the optical communication are mainly affected by the dispersion behavior of the refractive index which has been analyzed by the theory of the single effective oscillator model that was proposed previously by WempleDiDomenico (W-D) [18]. According to this model, the dispersion energy $E_{d}$ (which is a measure of the intensity of the inner band optical transitions), the single oscillator energy $E_{o}$ (which is considered as an average energy gap), and the refractive index $n$ are related to each other through the following formula [19]:

$$
n^{2}(E)=1+\frac{E_{d} E_{o}}{E_{o}^{2}-E^{2}}
$$

Using Eq. 6, the optical dispersion parameters including $E_{d}$ and $E_{o}$ were deduced from plotting $\left(n^{2}-1\right)^{-1}$ versus $E^{2}$ as shown in Fig. (6b). Therefore, the slope is $\left(E_{o} E_{d}\right)^{-1}$ and the intercept on the vertical axis represents $\left(\mathrm{E}_{\mathrm{o}} / \mathrm{E}_{\mathrm{d}}\right)$. The estimated values of $E_{d}$ and $E_{o}$ as illustrated in Table (2) show that the oscillator energy gap $\mathrm{E}_{\mathrm{o}}$, and the dispersion energy $E_{d}$, were decreasing by increasing the content of $\mathrm{CoCl}_{2}$ in the composites. The decrease in the dispersion energy $\mathrm{E}_{\mathrm{d}}$ of composites by $\mathrm{CoCl}_{2}$ gives an indication of decrease their bond strength [20]. In addition, $E_{o}$ can be used to deduce approximately the optical energy gap value $\left(E_{g}\right)$ by utilizing an empirical relation that was previously reported by Tanaka [21], i.e. $\mathrm{E}_{\mathrm{o}} \approx 2.23 \mathrm{E}_{\mathrm{g}}$ for the different composites whereas $\mathrm{E}_{\mathrm{o}} \approx 1.1 \mathrm{E}_{\mathrm{g}}$ for the pure blend of PVA/PEG 72/28 (wt.\%).

The static refractive index $\left(n_{0}\right)$ has been determined via extrapolating (E) to zero in Fig 6 b. So, Eq. 6 reduced to Tanaka formula as the following [21]:

$n_{o}=\sqrt{1+\frac{E_{d}}{E_{o}}}$

The static dielectric constant $\varepsilon_{\infty}$ has been deduced according to the following formula [21]:

$\varepsilon_{\infty \approx n_{o}^{2}}$

Table (2) presents the values of $\mathrm{n}_{\mathrm{o}}$ and $\varepsilon_{\infty}$ for the composites and the pure blend in which they decreased by increasing the content of the $\mathrm{CoCl}_{2}$. Also, it was found that the values of $n_{o}$ estimated at zero - E from (W-D) model, as seen in Table 2, were almost equal to the determined values of $n$ at long wavelengths as shown in Fig (6a) for pure blend (2.58) and the composites $(1.45,1.45$ and 1.26) from the lowest to the highest content of $\mathrm{CoCl}_{2}$, respectively.

The moments of the optical spectrum $\left(\mathrm{M}_{1}\right.$ and $\left.\mathrm{M}_{3}\right)$ can provide a measure of inter-band transition strengths, which are calculated as the following relations [21]:

$E_{o}^{2}=\frac{M_{1}}{M_{3}}$

$E_{d}^{2}=\frac{M_{1}^{3}}{M_{3}}$

Table (2) shows the values of $\mathrm{M}_{1}$ and $\mathrm{M}_{3}$ for all the composites in which they were decreasing with increasing the cobalt contents. The optical moments are associated to the macroscopic quantities as dielectric constants, effective number of valence electrons in the studied composites [22]. 


\section{Optical conductivity}

The optical conductivity $\sigma_{\mathrm{op}}$, represents the optical response of the tested sample material and it has the dimensions of frequency, which are valid only in the Gaussian system of units. $\sigma_{\text {op }}$ was obtained from the following formula [23]:

$\sigma_{\text {op }}=\frac{\alpha n c}{4 \pi}$

Where $c$ is the velocity of light in space, $\alpha$ is the absorption coefficient and $n$ is the refractive index. The variation of the optical conductivity $\sigma_{\text {op }}$ with the incident photon energy for the composites is shown in Fig. (7a). In the regions of wavelengths of (190-580 and 725-900) nm, the values of $\sigma_{\mathrm{op}}$ were decreasing by increasing the $\mathrm{CoCl}_{2}$ content in the blend due to the low absorbance of the films. However, in the range of the absorption band of $\mathrm{CoCl}_{2}$, from 580 to $725 \mathrm{~nm}, \sigma_{\text {op }}$ was increasing with $\mathrm{CoCl}_{2}$ content as a result of the high absorbance of the films in this region [24].

\section{Optical dielectric constants}

The well-known formula for the complex dielectric function is described by $\varepsilon=\varepsilon_{r}+\mathrm{i} \varepsilon_{i}$, where $\varepsilon_{r}$ is the real part and $\varepsilon_{i}$ is the imaginary part of dielectric constant. The real part of dielectric constant is associated with the dispersion which depends mainly on the motion of the electrons in the optical medium through the traveling of the light. On the contrary, the imaginary part is responsible of the dissipative rate of electromagnetic wave propagation in the medium. The real and imaginary parts of dielectric constant are described by the following equations [17]:

$$
\begin{aligned}
\varepsilon_{i} & =2 \mathrm{n} \mathrm{k} \\
\varepsilon_{r} & =\mathrm{n}^{2}-\mathrm{k}^{2}
\end{aligned}
$$

Fig. (7b, 7c) shows the dependence of $\varepsilon_{i}$ and $\varepsilon_{\mathrm{r}}$, respectively, on the photon energy $\mathrm{E}(\mathrm{eV})$ for all the different composites. Fig. (7b) shows that by increasing the content of $\mathrm{CoCl}_{2}$, the values of $\varepsilon_{i}$ were decreasing in all spectrums, but vice versa in the region of the cobalt chloride absorption (580 $725) \mathrm{nm}$. The increase of $\varepsilon_{i}$ in the absorption band of cobalt chloride depends on $k$ value which is essentially related to the change of absorption coefficients On the other hand, Fig. (7c) illustrates that the values of $\varepsilon_{\mathrm{r}}$ were decreased with increasing the content of $\mathrm{CoCl}_{2}$ in all range of the wavelengths which is the same attitude observed in case of the refractive index spectrum as seen previously in Fig. (6a). This behavior is due to that $\varepsilon_{\mathrm{r}}$ does effectively depending on the values of $\mathrm{n}^{2}$ owing to the small value of $\mathrm{k}^{2}$ which can be negligible [17].

\section{Penetration depth}

The penetration depth $(\delta)$ is known as skin depth and it expresses the exact distance that the electromagnetic wave can penetrate in to the polymeric material. The penetration depth was estimated by using the following relation [24]:

$\delta=\frac{1}{\alpha}$

Where $\alpha$ is the absorption coefficient. Fig. (8) shows the variation of the penetration depth $(\delta)$ with wavelength for the different contents of the composites. It can be observed, for all the studied films, that the penetration depth increases as the wavelength increases. However, by increasing the content of $\mathrm{CoCl}_{2}$ in the blend PVA/PEG 72/28 (wt.\%), the penetration depth $(\delta)$ shows an obvious decrease in its values, in the range of absorption of the cobalt chloride $(420 \mathrm{~nm}-750 \mathrm{~nm})$, due to increase the absorption possibility. Consequently, it is worth to say that the penetration depth is a transmittance related [24]. 

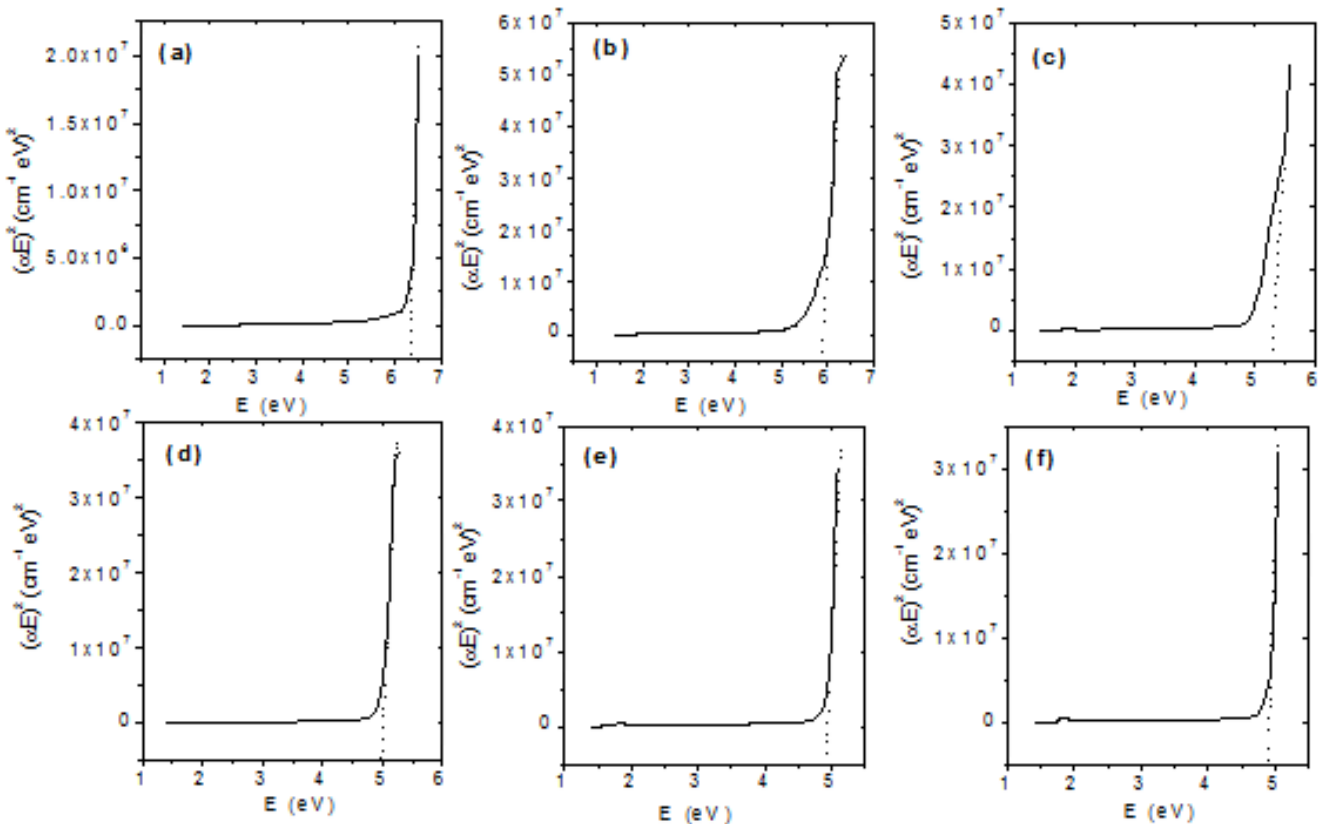

Fig. (4): The dependence of $(\alpha E)^{2}$ on the photon energy for cobalt chloride $\left(\mathrm{CoCl}_{2}\right)$ embedded in the blend of PVA/PEG 72/28 wt. \% with different contents (a) 0 wt. \%, (b) 4.76 wt.\%, (c) 11.1 wt.\%, (d) 14.0 wt.\%, (e) 16.2 wt.\% and (f) 19.2 wt.\%
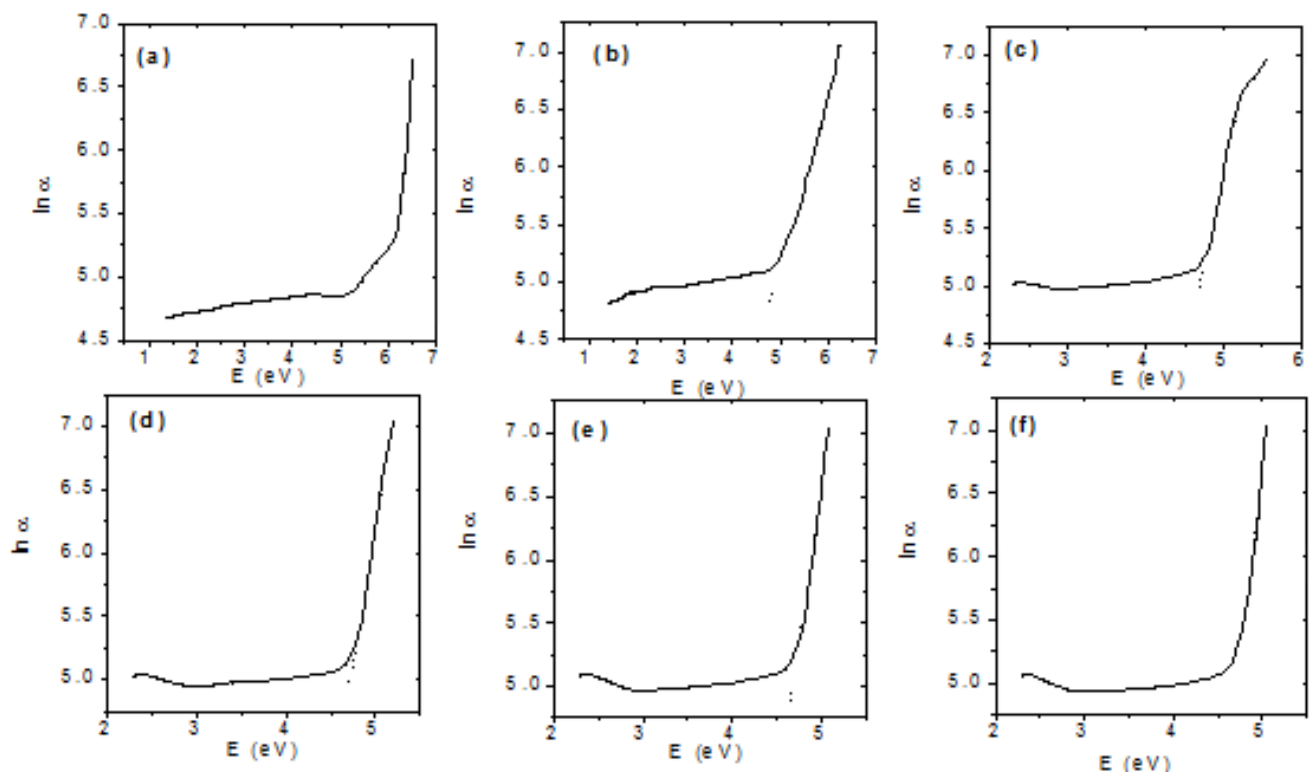

Fig. (5): The dependence of $\ln (\alpha)$ on the photon energy for cobalt chloride $\left(\mathrm{CoCl}_{2}\right)$ embedded in the blend of PVA/PEG 72/28 wt. \% with different contents (a) 0 wt. \%, (b) 4.76 wt. \%, (c) 11.1 wt. \%, (d) 14.0 wt. \%, (e) 16.2 wt.\% and (f) 19.2 wt. \%

Corresponding author: rania.7.8.2016@gmail.com

(C) Scientific Information, Documentation and Publishing Office (SIDPO)-EAEA 

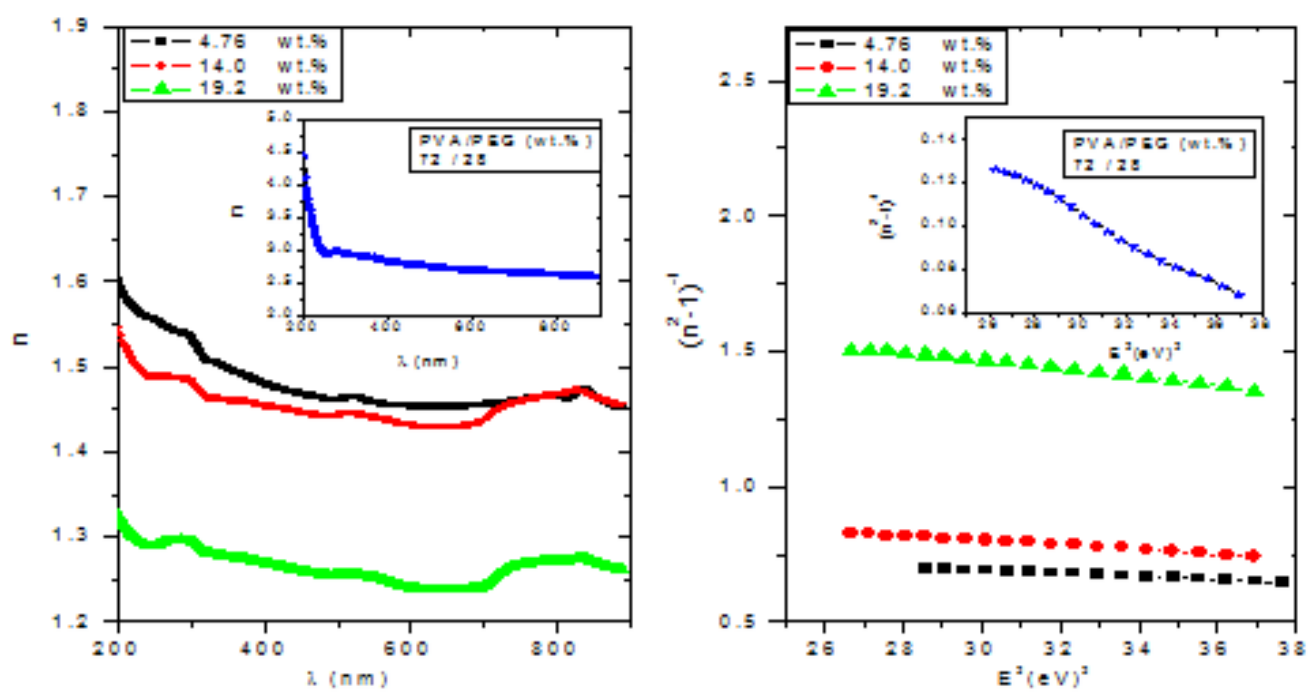

Fig. (6a): The variation of the refractive index with the wavelength for different contents of cobalt chloride $\left(\mathrm{CoCl}_{2}\right)$ embedded in the blend of PVA/PEG 72/28 wt.\%, (The inset is for pure blend). (b) Plots of $\left(\mathrm{n}^{2}-1\right)-{ }^{1}$ versus photo energy, $\mathrm{E}$ (eV) for different contents of cobalt chloride $\left(\mathrm{CoCl}_{2}\right)$ embedded in the blend of PVA/PEG 72/28 wt.\%, (The inset is for pure blend)

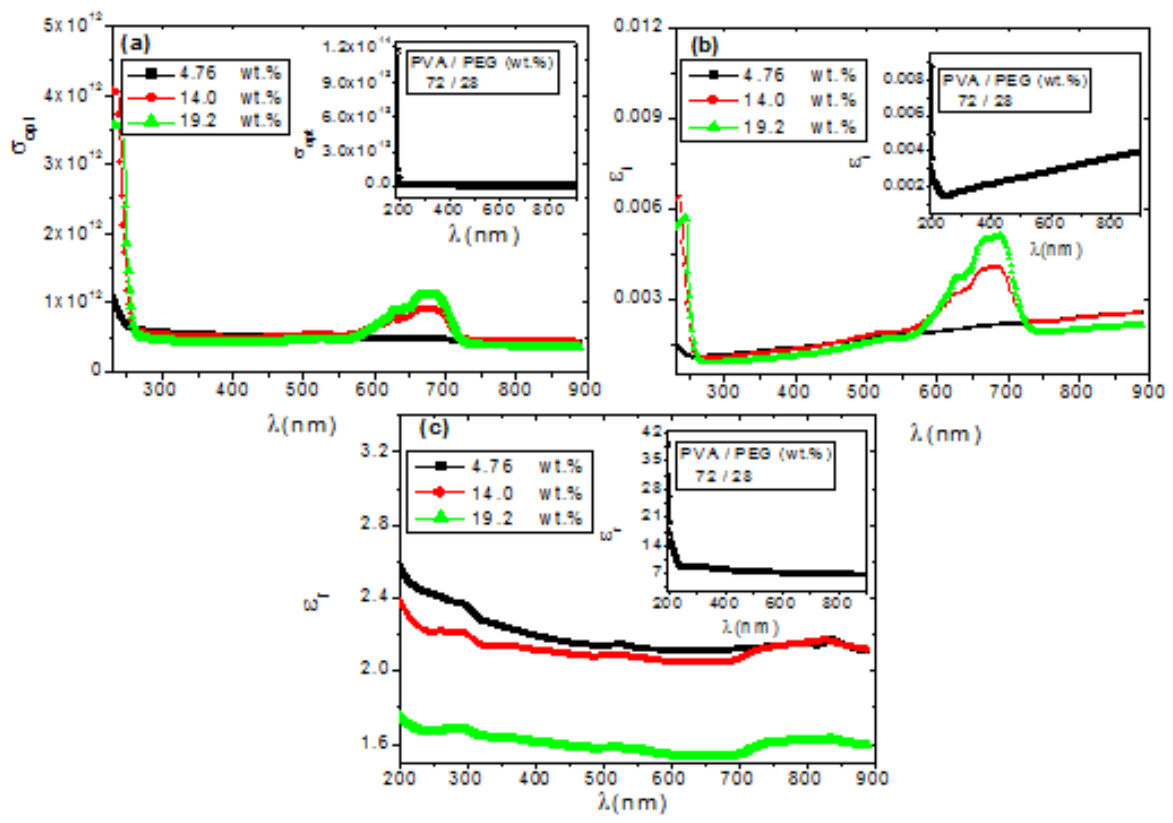

Fig. (7): The variation of (a) the optical conductivity (b) and (c) represent the imaginary part and the real part, respectively, of the dielectric constant with the wavelength for different contents of cobalt chloride $\left(\mathrm{CoCl}_{2}\right)$ embedded in the blend of PVA/PEG 72/28 wt.\%., (In all, the inset is for pure blend) 


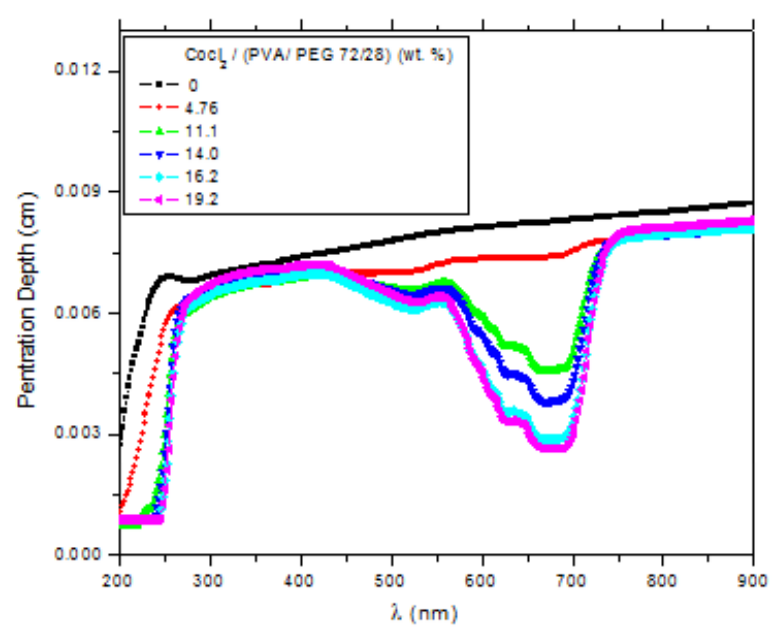

Fig. (8): The penetration depth for different contents of cobalt chloride $\left(\mathrm{CoCl}_{2}\right)$ embedded in the blend of PVA/PEG 72/28 wt. \%

\section{Conclusion}

Variant contents of cobalt chloride $\left(\mathrm{CoCl}_{2}\right)$ embedded in a blend of (PVA/PEG 72/28 wt. \%) were prepared by simple casting method to form their composite films. The change in the optical band gap of the composites is due to the formed localized states which play as trapping and recombination centers. The formation of free radicals can explain the reduction in the values of the Urbach energy depending on the content of $\mathrm{CoCl}_{2}$. The refractive index of the composites was decreased compared to that of the pure blend which

is a result of increasing the interatomic spacing. The results show that $\mathrm{E}_{\mathrm{o}} \approx 2.23 \mathrm{E}_{\mathrm{g}}$ for the different composites whereas for pure blend, $\mathrm{E}_{\mathrm{o}} \approx 1.1 \mathrm{E}_{\mathrm{g}}$. In the range of the absorption band of $\mathrm{CoCl}_{2}$, from 580 to $725 \mathrm{~nm}, \sigma_{\text {op }}$ was increasing with $\mathrm{CoCl}_{2}$ content due to the high absorbance of the films in this region. A slight shift in the positions of some bands of PVA and PEG was observed in the FT-IR spectra for the composites as a result of adding $\mathrm{CoCl}_{2}$ to the blend. The imaginary part of the optical dielectric constant as well as the optical conductivity showed a decrease in their values by increasing $\mathrm{CoCl}_{2}$ content except for the region of $\mathrm{CoCl}_{2}$ absorption $(580-725) \mathrm{nm}$. The real part of the dielectric constant of the composites is affected directly by the behavior of the refractive index spectrum; therefore it was decreasing by $\mathrm{CoCl}_{2}$. By increasing the content of $\mathrm{CoCl}_{2}$ in composites, the penetration depth $(\delta)$ decreased in the range of absorption of the $\mathrm{CoCl}_{2}(420 \mathrm{~nm}-750 \mathrm{~nm})$, because of increasing the absorption possibility.

\section{References}

1- Aziz, S.B., Ahmed, H.M., Hussein, A.M., Fathulla, A.B., Wsw, R.M. and Hussein, R.T. (2015) Tuning the absorption of ultraviolet spectra and optical parameters of aluminum doped PVA based solid polymer composites, J Mater Sci: Mater Electron, 26, 8022-8028.

2- Ahmed, R.M., (2014) Optical Properties and Structure of Cobalt Chloride Doped PVA and its Blend with PVP, IJMPB, 28 (5), 1450036.

3- Hassen, A., El Sayed, A.M., Morsi, W.M. and ElSayed, S. (2012) Influence of $\mathrm{Cr} 2 \mathrm{O} 3$ nanoparticles on the physical properties of polyvinyl Alcohol, J. Appl. Phys. 112, 093525.

4- Rabee, B.H. and Adel Hadi, N. (2014) Study the Effect of Nano-Mgo On the Optical Properties of (PVA-PEG-Mgo) Nanocomposites, IJERT, 3 (6), 2257-2260.

5- El Sayed A.M., Diab, H.M. and El-Mallawany, R. (2013) Controlling the dielectric and optical properties of PVA/PEG polymer blend via e-beam irradiation, J Polym Res, 20, 255.

6- Ramamohan, K., Achari, V.B.S., Sharma, A.K. and Xiuyang, Lu (2015) Electrical and structural characterization of PVA/PEG polymer blend electrolyte films doped with $\mathrm{NaClO} 4$, Ionics 21, 1333-1340.

7- Majhi, M., Choudhary, R.B. and Maji, P. (2015) $\mathrm{CoCl} 2$ reinforced polymeric nanocomposites of conjugated polymer (polyaniline) and its conductive properties, Bull. Mater. Sci., 38 (5), 1195-1203.

8- Deshmukh, K., Ahamed, M. B., Sadasivuni, K.K., Ponnamma, D., Deshmukh, R.R., Pasha, S.K.K., AlMaadeed, M.A. and Chidambaram, K. (2016) Graphene oxide reinforced polyvinyl alcohol/polyethylene glycol blend composites as high-performance dielectric material, J Polym Res., $23, .159$. 
9- Mansour, A.F., Ahmed, R.M., Bassyouni and A.H., Nasr, G. M. (2007) Optical Properties of GammaIrradiated ST/MMA Copolymer, Int. J. Polym. Mater. 56, 207-226.

10- Ahmed, R.M. (2009) Optical Study on Poly(methylmethacrylate)/Poly(vinyl acetate) Blends. Int. J. Photoenergy, 2009, 150389.

11- Ahmed, R.M. and El-Bashir, S.M. (2011) Structure and Physical Properties of Polymer Composite Films Doped with Fullerene Nanoparticles, Int. J. Photoenergy. 2011, 801409.

12- Ahmed, R.M. (2008) Study on Different SolutionCast Films of PMMA and PVAc, Int. J. Polym. Mater. 57, 969-978.

13- Ahmed, R.M. (2017) Surface and Spectroscopic Properties of CdSe/ZnS/PVC Nanocomposites, Polym. Compos. 38, 749 -758.

14- Mansour, A.F., Ahmed, R. M., Bassyouni, A.H. and Nasr, G. (2007) Optical Spectroscopic Studies of Perylene Dye Doped in Copolymer of ST/MMA as Solar Collector, Int. J. Polym. Mater. 56, 651-662.

15- Prasher, S., Kumar, M. and Singh, S. (2014) Electrical and optical properties of O6+ Ion BeamIrradiated polymers, Int. J. Polym. Anal. Charact., 19, 204-211.

16- Chapi, S. and Devendrappa, H. (2015) Influence of cobalt (II) chloride catalysed on the thermal and optical characterization of PEO based solid polymer electrolytes, J. Res. Updates Polym. Sci., 3 (4), 205-215.
17- Ghanipour, M. and Dorranian, D. (2013) Effect of Ag-Nanoparticles Doped in Polyvinyl Alcohol on the Structural and Optical Properties of PVA Films, J Nanomater. 2013, 897043.

18- Abdullah, O.Gh., Saber, D.R. and Taha, S.A. (2015) The optical characterization of polyvinyl alcohol: cobalt nitrate solid polymer electrolyte films, Adv. Mater. Lett., 6(2), 153-157.

19- Abdelaziz, M. (2011) Cerium (III) doping effects on optical and thermal properties of PVA films, Physica B, Physica B 406, 1300-1307.

20- Abdullah, O.Gh., Salman, Y.A.K. and Saleem, S.A. (2015) In-situ Synthesis of PVA/HgS Nanocomposite Films and Tuning Optical Properties, Physics and Materials Chemistry, 3 (2) 18-24.

21- Habubi, N.F., Mishjil, K.A. and Chiad, S.S. (2013) Structural properties and refractive index dispersion of cobalt doped $\mathrm{SnO} 2$ thin films, Indian J Phys, 87 (3), 235-239.

22- Mahdi, M.A. and Al-Ani, S.K.J. (2012) Optical characterization of chemical bath deposition Cd1$x Z n x S$ thin films, Int. J. Nanoelectronics and Materials 5, 11-24.

23- Rubee, B.H., Abd AlHussien, S. (2016) Study of Optical Properties for (PVA-PEG-ZnO) Nanocomposites, IJSR, 5, 1794-1799.

24- Al-Taa'y, W.A., Oboudi, S.F., Yousif, E., Abdul Nabi, M. Yusop, R.M., Derawi, D. (2015) Fabrication and Characterization of Nickel Chloride Doped PMMA Films, Adv. Mater. Sci. Eng. 2015, 913260. 